\title{
Development and validation of the maternal blues scale through bonding attachments in predicting postpartum blues
}

\author{
Suryani Manurung, S. Setyowati
}

Manurung S, Setyowati S. Development and Validation of the Maternal Blues Scale Through Bonding Attachments in Predicting Postpartum Blues. Malays Fam Physician. 2021;16(1);64-74. https://doi.org/10.51866/oa1037

\section{Keywords:}

Questionnaire development,

postpartum blues, internal

and external indicators,

Indonesia

\section{Authors:}

\section{S. Setyowati}

(Corresponding author)

Professor

Maternity Nursing Department

Faculty of Nursing Universitas

Indonesia

Email: wati123@ui.ac.id

\section{Suryani Manurung}

Lecturer

Maternity Nursing Department

Health Polytechnic Jakarta I

Indonesia

\section{Abstract}

Background: Postpartum blues in Indonesia has a high prevalence at 37\% to 67\%. Postpartum blues syndrome has been described as varying changes in the affective domain, such as feelings, behavior, or thoughts, that can be influenced by the roles and tasks of women, along with their social, cultural, and economic support. Instruments that measure maternal blues through bonding attachment behavior have never before been developed in Indonesia.

Objective: This study aimed to develop a maternal blues scale through bonding attachments to predict postpartum blues.

Method: The research design consisted of three stages: 1) phenomenology design and focus group discussion; 2) development and construction of the maternal blues scale, and 3) a cross-sectional study to measure validation of the scales. Respondents were postpartum mothers in the first week after birth. The sample comprised 501 participants. Sampling was done by consecutive sampling at the Public Health Center (PUSKESMAS) in the South Jakarta area. Data analysis used exploratory factor analysis (EFA) and confirmatory factor analysis (CFA), correlation, and a diagnostic testing .

Results: Item analysis produced 32 items consisting of 24 items regarding the mother's role and duties as internal factors and eight factors involving social, cultural, and economic support as external factors. Both factors were valid and reliable in predicting postpartum blues with indicators ( $\mathrm{t}$ loading factors $\geq 1.96$, standardized loading factor $(\mathrm{SLF}) \geq .50$, internal factors: construct reliability $(\mathrm{CR}) \geq .70$ and extraction variants $(\mathrm{VE}) \geq .50$ and external factors: $\mathrm{CR} \geq .74$ to $.83 \mathrm{VE} \geq .50$ to .63$)$. The relationship with Kennerley's maternity blues as a gold standard was significant. Internal factors had a score of 53 , with a sensitivity of $60.2 \%$. The external factors score was 19 , with a sensitivity of $77.3 \%$.

Conclusion: The new scale for postpartum blues prediction developed displayed internal consistency and validity of each indicator (internal and external factors) that was good ( $\mathrm{CR} \geq .70$; VE $\geq .50$ ). This scale provides a feasible tool to predict postpartum blues.

\section{Introduction}

Depression, a change in the affective domain that describes mental and emotional conditions, most often occurs in general population especially during postpartum period. ${ }^{1}$ Changes in mental and emotional conditions take place from an early phase after birth (postpartum blues) and put mothers at risk of beginning in the early stage with post partum blues and progressing with time to post partum depression and psychosis. ${ }^{2} 80 \%$ of new mothers experience postpartum blues, and $10-15 \%$ of those cases progress to postpartum depression. ${ }^{1}$ The prevalence of postpartum blues in Indonesia is quite high, at $37 \%$ to $67 \%$. $^{3,4}$ Postpartum blues are likely to be predictors of postpartum depression by $15 \%$ to $20 \%{ }^{1}$ The progression of postpartum blues to major depression must be prevented due to the risk that mothers might become triggered to engage in self-injury, suicide, or abandoning their babies. $^{5}$

Depressive symptoms are found in most of the postpartum women that describe changes in the affective domain and may vary from person to person in such areas as feelings, behavior, and thoughts, from mild to severe intensity. ${ }^{6}$ This syndrome takes place during the transition phase in the perinatal period. Changes in affective domains may worsen, for example, displayed in such reactions as disliking pregnancy and the birth of the baby or patterns of maternal interaction with infants. ${ }^{7-9}$ Previous researchers have also suggested that postpartum depression is related to the affective domain of bonding attachments. This concept was tested on the maternal postnatal attachment scale (MPAS) 
scale and Edinburgh postnatal depression scale (EPDS) scale, revealing a correlation between both postpartum depression and bonding attachments. ${ }^{10,11}$

Based on a literature review and previous research, several factors emerged that influence postpartum depression and the failure of bonding attachments, including roles and tasks as mothers during the transition phase as well as social, cultural, and economic support. ${ }^{12,13}$ Symptoms of postnatal depression include the inability to carry out mothering tasks, becoming angry with continuing tasks, poor self care, and finding a mother's work burdensome. ${ }^{14,15}$

Cultural tradition was another factor that some researchers found could trigger depression and bonding attachment failure. ${ }^{16}$ Local community and family values that prioritize one sex of children over the other can significantly trigger domestic violence and influence behavior involving rejecting the presence of babies. ${ }^{17}$ Other traditional behaviors in caring for mothers after childbirth include restricted activities, staying at home for a month, or forbidding certain foods. Such restrictions can exert an influence on mothers' emotions, especially in terms of interacting with their baby, causing them to blame the baby for such restrictions. ${ }^{16}$

Economic factors (especially family income) have been found to relate to depressive symptoms and bonding attachment failure. ${ }^{18}$ Economic status can cause low interest or desire to interact with infants and increased stress. ${ }^{18,19}$ The results of the literature review illustrate that postpartum blues can be detected through the affective domain in observing mothers' interactions with their infants (bonding attachment). ${ }^{1,6}$ Studies investigating postpartum blues have previously been carried out using a scale developed by Pitt, Stein, and Kennerley. ${ }^{20}$ The measuring instrument was originally developed in a different culture from that in Indonesia, based on factors such as depression, anxiety, somatic abnormalities, and personality to describe the condition of the affective domain in measuring postpartum blues.

This study aimed to develop a maternal blues scale related to the affective domain in interacting with infants (bonding attachment) to predict postpartum blues. Measuring instruments were developed based on factors involving mothers' roles and tasks along with social, cultural, and economic support in accordance with Indonesian culture. The scale was validated to measure its validity and reliability in predicting postpartum blues. The purpose of developing this scale measuring maternal blues through the affective domain of interacting with infants (bonding attachment) was to maximize maternal care and infant welfare. $^{1}$

\section{Methods}

\section{Research design}

The study design consisted of three stages. Stage one used a qualitative method, a phenomenology design that employed indepth interviews and focus group discussion. ${ }^{16}$ The study population included pregnant women and women who had already experienced motherhood in Depok Sawangan West Java and the South Tanggerang District. Stage two involved constructing the maternal blues scale through the affective domain of interacting with infants (bonding attachment), which was carried out through an item generation process that reflected information gathered in the previous qualitative study. Item generation produced 65 items in the form of statements, developed from the factors of mothers' roles and duties as well as social, cultural, and economic support.

Stage three was a cross-sectional study designed to validate the scales. ${ }^{21}$ The development and validation processes included the following steps: 1$)$ assessing the validity and reliability of 65 items from the draft item statement on the factors of mothers' roles and duties and social, cultural, and economic support; 2) assessing the validity and reliability of maternal roles and tasks as well as social, cultural, and economic support for the postpartum blues construct; 3) conducting parallel tests between the maternal blues scale based on Kennerley's maternity blues 3) measuring the sensitivity of the developed maternal blues scale in predicting postpartum blues.

The following flowchart illustrates the research process used to develop the postpartum blues scale. 


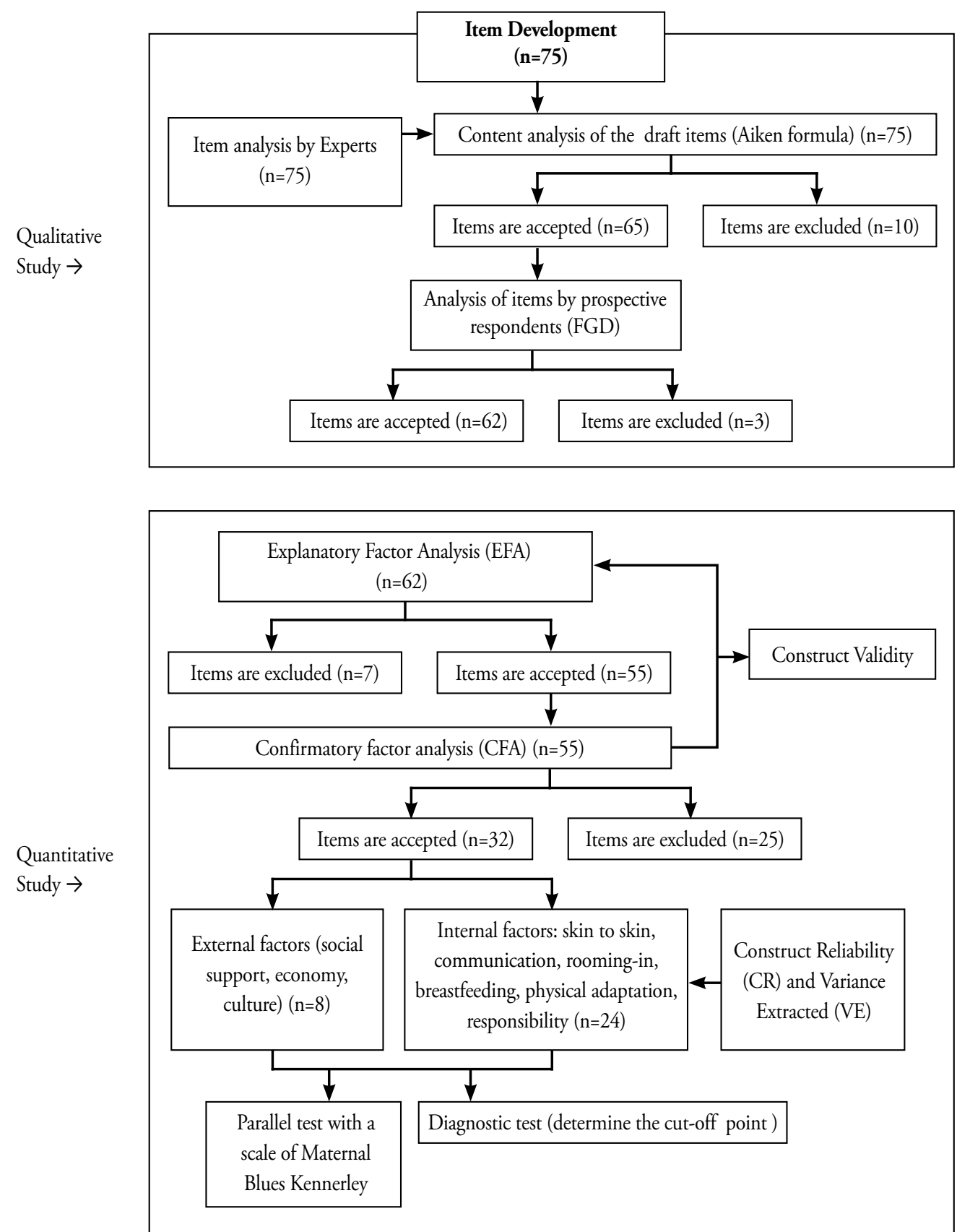

Figure 1: Flowchart of the process of developing the maternal blues scale.

\section{Setting and sample}

The study was conducted in five public health centers (Puskesmas) in South Jakarta that had a relatively high delivery rate ( \pm 50 deliveries/ month). Randomly selected Puskesmas were Jagakarsa, Pasar Minggu, Tebet, Cilandak Barat, and Kebayoran Lama. Data collection used the maternal blues scale questionnaire and Kennerley's maternity blues scale, which was translated into Indonesia. Data were gathered by data collectors in each Puskesmas from January to June 2017. Data collectors were trained and familirized with the new maternal blues scale and Kennerley maternity blues scale questionnaires. Parallel tests was conducted on the maternal blues scale and were constructed with the Kennerley model's maternal blues scale. This test is to see the correlation of the two scales in measuring postpartum blues. The results obtained illustrate the two scales have a significant relationship $(\mathrm{P}<.01)$. This data illustrates that the two scales represent the same data. Correlation of two scales was significant (.30). The magnitude of the correlation reflects the difference between the two scales in showing the occurrence of postpartum blues. The maternal blues scale that is constructed describes the affective domain in interacting with infants (bonding attachment) while 
the Kennerley model's maternal blues scale describes the condition of the affective domain.

Then a correlation test was conducted between internal factors: the role and task of mothers with external factors, namely supporting sources: culture, social and economic support from the maternal blues scale that was built. The results obtained that these two factors have a significant relationship $(\mathrm{P}<.01)$. The correlation between internal and external factors is strong (>.6).

The new maternal blues scale draft questionnaire was designed as a Likert scale with positive and negative statements. The answer options included very appropriate, appropriate, ordinary, inappropriate, and very inappropriate.

The participants in the study sample came from the postpartum maternal population. The sample inclusion criteria included normal labor, live birth, and no complications after childbirth. Sampling was carried out using a consecutive sampling technique. Study participants selected in accordance with the inclusion criteria numbered 501 mothers.

\section{Data collection and analysis}

Data were obtained from participants who were in the health center, in a ward postpartum, or who came in for a checkup on the fifth or seventh day postpartum. Data collection was done one time using one measurement. The data were processed using several measurement methods to produce fix items that were formulated to predict postpartum blues. The software packages used to analyze the data were the Lisrel program (2006) and SPSS version 19.

The selection of the maternal blues scale items was carried out by analysis of structural equation modeling (SEM). The initial analysis involved exploratory factor analysis (EFA), which tested the feasibility of the draft item as part of the initial modeling. Confirmatory factor analysis (CFA) was used to match the item (goodness of fit) based on the value of validity and reliability to predict postpartum blues. Some indicators of validity and reliability included $t$ value, standardized loading factor (SLE), extracted variance (VE), and construct reliability (CR). ${ }^{22}$

Parallel test analysis compared the maternal blues scale with Kennerley's maternity blues scale model. The comparison between the two measuring instruments was analyzed to arrive at a tool that could predict postpartum blues. ${ }^{23}$

The new maternal postpartum blues scale has been developed as a screening tool. The sensitivity tests were carried out by using the receiver operating characteristic (ROC) method. ${ }^{23}$

\section{Principles of Ethics}

The ethical principle applied during the research was the principle of beneficence, which involves respect for human dignity and justice. Before the questionnaire was distributed to the participants, informed consent was obtained by providing information about the research activities, followed by signing the agreement. Participants were given the opportunity to refuse or indicate their willingness to participate. The research activities satisfied ethical requirements and received approval from the ethics committee of the Faculty of Nursing University of Indonesia.

\section{Results}

Respondents selected in accordance with the inclusion criteria numbered 501 people. The number of respondents who were surveyed in the process of developing the scale has been fulfilled according to the criteria. The respondents completed filling out the draft scale of the maternal blues questionnaire with 65 items in the form of statements and the maternity blues scale from Kennerley's model. The average age of respondents was $28.98 \pm$ SD 5.98 years (aged between 16 to 46 years). The minimum number of maternal parity was one, and the maximum was seven children.

\section{Item analysis}

Preliminary modeling was carried out using due diligence with EFA analysis. The item statements selected in the initial modeling included 54 items, consisting of groups: maternal role and task factors (41 items), social support (six items), and culture and economy (seven items). The indicator criteria of the results of the feasibility test produced included the value of the Bartlett test of sphericity with a chi-square with p-value $<.001$. This indicator reveals a significant correlation between the observed variables. The value of Kaiser-MeyerOlkin (KMO) was equal to .908 with a p-value 
$<.05$; internal consistency (Alpha Cronbach's was .45 to .91). Based on the above indicators, 54 statement items were feasible for a model match test with CFA analysis.

The model suitability measurement for the 54 items aimed to measure the validity and reliability of 1) the relationship between item with factors of mothers' roles and tasks, along with social, cultural, and economic support and 2) the relationship between the factors of mothers' roles and tasks as well as social, cultural and economic support and the postpartum blues construct. The results of the model suitability measurements on the 54 items indicated seven factors, with 32 items having statements suitable for describing postpartum blues. Analysis of the seven factors in the 32 statement items is shown in Tables $\mathbf{1}$ to 3 .

Table 1: Measurement of Items Statement of Internal Factors: Role and Tasks of Mother in Interacting with Infants (Bonding Attachment) to Predict Postpartum Blues ( $\mathrm{n}=501)$.

\begin{tabular}{|c|c|c|c|c|c|}
\hline $\begin{array}{l}\text { Latent variable } \\
\text { Mother's roles } \\
\text { and duties }\end{array}$ & $\begin{array}{l}\text { Indicator variable (item statement) } \\
\text { and item statement number }\end{array}$ & $\begin{array}{l}\text { Standardized } \\
\text { Loading Factor } \\
(\mathbf{S L F}) \geq \mathbf{0 . 5 0}\end{array}$ & $\begin{array}{c}T \\
\text { value }\end{array}$ & $\begin{array}{l}\mathrm{CR} \geq \\
0.70\end{array}$ & $\begin{array}{l}\mathrm{VE} \geq \\
0.50\end{array}$ \\
\hline \multirow{10}{*}{$\begin{array}{l}\text { F1: } \\
\text { skin to skin, } \\
\text { communication, } \\
\text { rooming in }\end{array}$} & Happy when in contact with baby's skin (4). & .74 & 15.3 & \multirow{10}{*}{.95} & \multirow{10}{*}{.61} \\
\hline & Happy when I see baby comfortable when hugged (3). & .70 & 9.9 & & \\
\hline & $\begin{array}{l}\text { Happy when baby found comforted by hearing my } \\
\text { voice (6). }\end{array}$ & .74 & 10.29 & & \\
\hline & Happy when the baby is in my arms (9). & .75 & 10.23 & & \\
\hline & Pray for baby’s health (7). & .69 & 9.94 & & \\
\hline & Happy when baby with me all day (20). & .71 & 10.00 & & \\
\hline & Tired of giving birth lost when hugging a baby (1). & .48 & 15.38 & & \\
\hline & Families give confidence to care for babies (56). & .63 & 9.44 & & \\
\hline & Feels convenient to talk with my baby (44). & .62 & 9.37 & & \\
\hline & I feel that caring for a baby all day is a burden (23). & .64 & 9.55 & & \\
\hline \multirow{8}{*}{$\begin{array}{l}\text { F2: } \\
\text { breastfeeding }\end{array}$} & Tired of nursing their baby (14). & .71 & 11.06 & \multirow{8}{*}{.87} & \multirow{8}{*}{.50} \\
\hline & Hate because of time wasted on breastfeeding (17). & .72 & 11.13 & & \\
\hline & $\begin{array}{l}\text { Hate because the baby does not want to stop } \\
\text { breastfeeding (19). }\end{array}$ & .66 & 10.66 & & \\
\hline & Tired of caring for babies throughout the day (21). & .73 & 11.24 & & \\
\hline & Breastfeeding a baby for a long time is fun (18). & .67 & 10.13 & & \\
\hline & Baby presence interferes with family needs (50). & .66 & 10.59 & & \\
\hline & Whenever I give breastfeed, I do it happily (15). & .63 & 9.51 & & \\
\hline & Hope the baby does not interfere while resting (10). & .53 & 15.04 & & \\
\hline \multirow{3}{*}{$\begin{array}{l}\text { F3: } \\
\text { physical } \\
\text { adaptation }\end{array}$} & $\begin{array}{l}\text { Worried, my husband doesn't accept my body changes } \\
\text { (34). }\end{array}$ & .75 & 15.49 & \multirow{3}{*}{.81} & \multirow{3}{*}{.50} \\
\hline & $\begin{array}{l}\text { Hate heart because I don't have time to take care of } \\
\text { myself (32). }\end{array}$ & .74 & 12.16 & & \\
\hline & I stress doing family advice in caring for babies (35). & .76 & 13.04 & & \\
\hline \multirow{3}{*}{$\begin{array}{l}\text { F4: } \\
\text { responsibility }\end{array}$} & Worried, I can't take care of the baby. (27) & .50 & 7.86 & \multirow{3}{*}{.65} & \multirow{3}{*}{.69} \\
\hline & I cry every time the baby cries (26). & .58 & 12.41 & & \\
\hline & Worried about a mother's resposibilities (30). & .67 & 9.02 & & \\
\hline
\end{tabular}

Table 1 illustrates the compatibility of internal factor models for predicting postpartum blues. Confirmatory analysis produced 24 items suitable for predicting postpartum blues through the affective domain (feelings, attitudes, and behaviors through the role and tasks of the mother in interacting with the baby). The item was developed from six factors: skin-to-skin contact, rooming in, communication, breastfeeding, physical adaptation, and responsibility. 
Table 2: Measurement of Statement Item External factors: Culture, Social Support, Economic for Predicting Postpartum Blues $(\mathrm{n}=501)$

\begin{tabular}{|c|c|c|c|c|c|}
\hline $\begin{array}{l}\text { Supporting } \\
\text { Resources: culture, } \\
\text { social support, } \\
\text { economy }\end{array}$ & $\begin{array}{l}\text { Indicator variable (item statement) } \\
\text { and item statement number }\end{array}$ & $\begin{array}{l}\text { Standardized } \\
\text { Loading Factor } \\
(\mathbf{S L F}) \geq \mathbf{0 . 5 0}\end{array}$ & $\begin{array}{c}T \\
\text { value }\end{array}$ & $\begin{array}{l}\mathrm{CR} \geq \\
0.70\end{array}$ & $\begin{array}{l}\mathrm{VE} \geq \\
0.50\end{array}$ \\
\hline \multirow{3}{*}{$\begin{array}{l}\text { F5: } \\
\text { Culture } \\
\text { (family acceptance) }\end{array}$} & $\begin{array}{l}\text { Worried when my baby care does not match the } \\
\text { family's expectations ( } 37) \text {. }\end{array}$ & .73 & 10.75 & \multirow{3}{*}{.74} & \multirow{3}{*}{.50} \\
\hline & $\begin{array}{l}\text { Sad if family doubts my ability to take care of a } \\
\text { baby (36). }\end{array}$ & .71 & 10.68 & & \\
\hline & $\begin{array}{l}\text { Worried if the baby is not in line with family } \\
\text { expectations (11). }\end{array}$ & .58 & 13.33 & & \\
\hline \multirow{3}{*}{$\begin{array}{l}\text { F7: } \\
\text { Economic factors } \\
\text { (Informational and } \\
\text { economic supports) }\end{array}$} & $\begin{array}{l}\text { I feel a heavy burden carrying out parental advice } \\
\text { in caring for babies (53). }\end{array}$ & .74 & 13.04 & \multirow{3}{*}{.83} & \multirow{3}{*}{.63} \\
\hline & $\begin{array}{l}\text { I am stressed when parents advise about caring } \\
\text { for babies ( } 52) \text {. }\end{array}$ & .84 & 14.09 & & \\
\hline & $\begin{array}{l}\text { I feel stressed with the current economic } \\
\text { conditions (51). }\end{array}$ & .62 & 14.26 & & \\
\hline \multirow{2}{*}{$\begin{array}{l}\text { F8: } \\
\text { Social Support } \\
\text { (Emotional and } \\
\text { appraisal support) }\end{array}$} & $\begin{array}{l}\text { My weakness in caring for a baby by mother } \\
\text { in-laws (58). }\end{array}$ & .57 & 6.54 & \multirow{2}{*}{.50} & \multirow{2}{*}{.30} \\
\hline & Confident in caring for babies (57). & .50 & 7.73 & & \\
\hline
\end{tabular}

Table 2 illustrates the compatibility of the external factor models to predict postpartum blues.

Table 3: Compatibility Test of Statement Items Internal and External Factors in Predicting Postpartum Blues $(\mathrm{n}=501)$.

\begin{tabular}{|c|c|c|c|c|c|}
\hline Variable & $\begin{array}{c}\text { Variable Indicators } \\
\text { (Internal and External Factors) }\end{array}$ & $\begin{array}{l}\text { Standardized } \\
\text { Loading Factor } \\
(\mathbf{S L F}) \geq \mathbf{0 . 5 0}\end{array}$ & $\begin{array}{c}T \\
\text { value }\end{array}$ & $\begin{array}{l}\mathrm{CR} \geq \\
0.70\end{array}$ & $\begin{array}{l}\mathrm{VE} \geq \\
0.50\end{array}$ \\
\hline \multirow{9}{*}{ Postpartum blues } & Internal factor (Mother's role and tasks) & & & \multirow{9}{*}{.92} & \multirow{9}{*}{.62} \\
\hline & F1 (skin to skin, communication, rooming in) & .72 & 9.46 & & \\
\hline & F2 (Breastfeeding) & .89 & 11.44 & & \\
\hline & F3 (Physical adaptation) & .85 & 15.53 & & \\
\hline & F4 (Responsiveness) & .70 & 9.03 & & \\
\hline & External factor (culture, social, economic support) & & & & \\
\hline & F5 (family acceptance) & .70 & 10.16 & & \\
\hline & F7 (informational and economic) & .91 & 13.44 & & \\
\hline & F8 (emotional and appraisal) & .72 & 10.56 & & \\
\hline
\end{tabular}

Table 3 displays internal and external factors. Statement items from internal and external factors were combined and analyzed again in predicting postpartum blues. Conformity test results of the statement items of the two factors were declared valid and can be relied upon to predict postpartum blues with criteria indicators (standard loading values .50, t values 1.96, CR .70, and VE .50).

Based on the degree of suitability of the model with absolute measure and incremental fit measure, 32 items were declared suitable in describing empirical data of postpartum blues. The results of the measurement of the model's suitability with the indicator criteria (absolute measure value: $\mathrm{RMSEA}=.074$ (good fit), GFI .80 (marginal match), and incremental fit measure $(\mathrm{NFI}=.93($ good match); NNFI $=$. $94(\operatorname{good}$ fit $)$, and CFI $=.89($ marginal fit $))$.
The results of the analysis of the statements in each of the items indicate that social, emotional, and appraisal support were not reliable but when in the analysis of all items obtained reliable and valid (values .50 , $\mathrm{t}$ values 1.96, CR .70, and VE .50). This outcome indicated mothers' failure to interact with their babies (bonding attachment). 


\section{Parallel test}

Parallel tests were conducted on the maternal blues scale constructed using the Kennerley model's maternity blues scale. This test aimed to determine the correlation between the two scales in measuring postpartum blues. The results obtained demonstrated that the two scales have a significant relationship ( $\mathrm{P}$ $<.01$, illustrating that the two scales represent the same data. The correlation between the two scales was .30. The magnitude of the correlation reflects the difference between the two scales in showing the occurrence of postpartum blues. The maternal blues scale that was constructed describes the affective domain in interacting with infants (bonding attachment), while the Kennerley model's maternity blues scale describes the condition of the affective domain with a coefficient of 0.85 (72-84 items), which is parallel with the new maternal blues scale ( 54 items) having a total value of items according to Cronbach's alpha as follows: F1: 0.882, F2:0.854, F3: 0.796, F4: 0.621, F5: 0.701, F5: 0,754, F8: 0.5.

Next, a correlation test was conducted between internal factors (the role and tasks of mothers) and external factors (i.e., supporting sources including cultural, social, and economic support) from the maternal blues scale that was developed. The results revealed that these two factors have a significant relationship $(\mathrm{P}<.01)$. The correlation between internal and external factors is strong (>.6).

\section{Diagnostic test}

This measurement was carried out on internal and external factors from the maternal blues scale that was developed. This measurement aimed to identify the presence of postpartum blues. It can also serve as a screening tool for predicting postpartum blues, as shown in Figures $\mathbf{2}$ and $\mathbf{3}$.

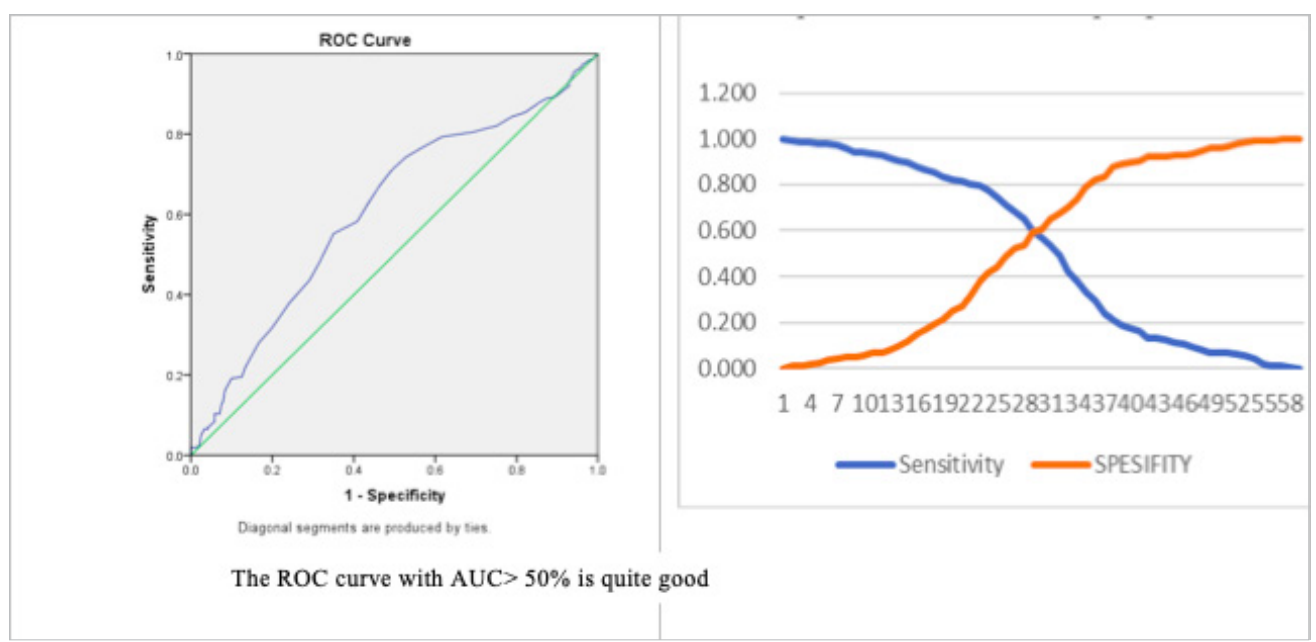

Figure 2: The Sensitivity and Specificity of Internal Factors Maternal Blues Scale

Figure 2 shows the results of the measurement of diagnostic tests on internal factors of the maternal blues scale. The Area Under the Curve (AUC) value is 61\% (95\% CI $55.7 \%-65.6 \%) \mathrm{p}<.05$. Based on confidence intervals, internal factors (the role and tasks of the mother) can predict the incidence of postpartum blues around $55.7 \%$ to $65.6 \%$ accuracy. The maternal blues scale that was developed could predict postpartum blues of $61 \%$ of 100 postpartum maternal population. Based on the intersection of the sensitivity and specificity curve, the internal factor score obtained in predicting postpartum blues was 53 , with a sensitivity of $60.2 \%$.

Figure 3 shows the results of the measurement of diagnostic tests for external factors from the maternal blues scale that was developed. The Area Under the Curve (AUC) value is 76.9\% (95\% CI 72.9-80.9\%) p <0.05. Based on confidence intervals, external factors (supporting sources including culture, social, and economic support) can predict postpartum blues events around $72.9 \%$ to $80.9 \%$ accuracy. The maternal blues scale that was developed could predict postpartum blues of 100 postpartum maternal population by $76.9 \%$ accuracy. The intersection of the sensitivity and specificity curves yielded an external factor score of 19 with a sensitivity of $77.3 \%$. Thus, the external factors described the risk factors for the occurrence of postpartum blues. 


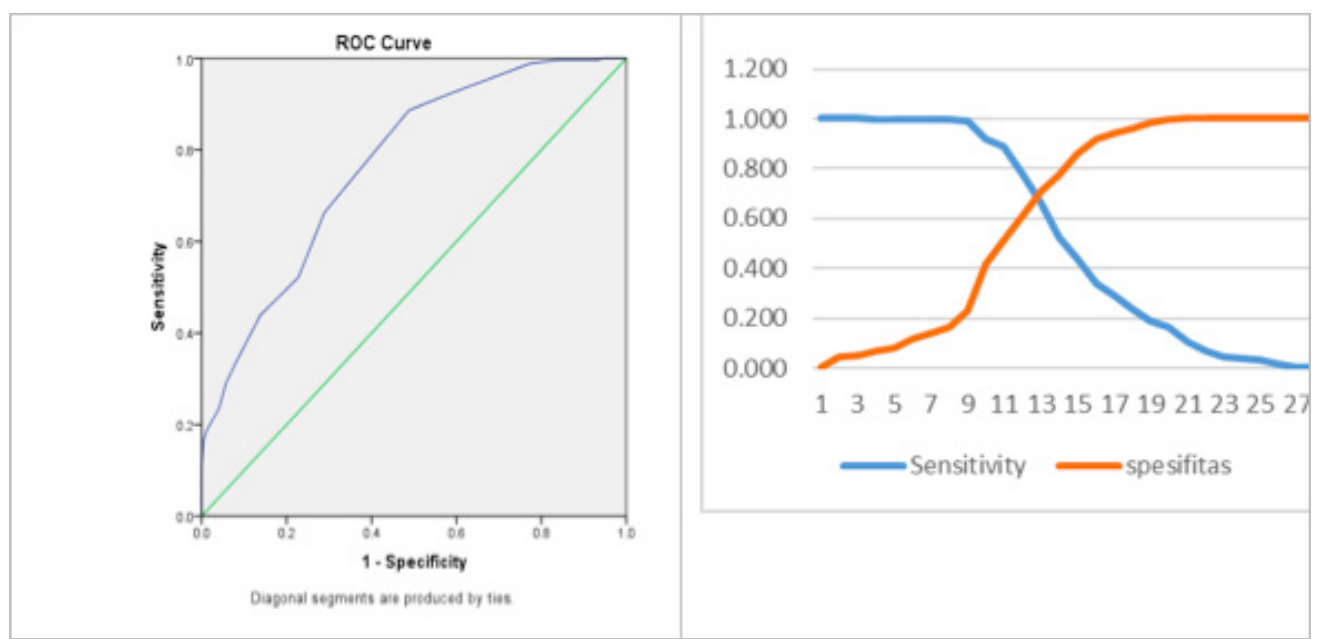

The ROC curve with AUC> $50 \%$ is quite good

ROC: receiver operating characteristic; AUC: area under the curve

Figure 3: Sensitivity and Specificity of External Factors Maternal Blues Scale

Table 4. The Comparison between Suryani's Model Instrument to Kennerley's Model in Measuring the Maternal Blues Scale $(n=120)$

\begin{tabular}{|c|c|c|c|c|c|}
\hline \multirow{2}{*}{$\begin{array}{l}\text { Suryani's Maternal } \\
\text { Blues Scale }\end{array}$} & \multicolumn{2}{|c|}{ Kennerley's Maternity Blues Scale } & \multirow{2}{*}{$\mathbf{p}$} & \multirow{2}{*}{ OR } & \multirow{2}{*}{ IC $95 \%$} \\
\hline & Blues & No Blues & & & \\
\hline Blues & $\begin{array}{c}51 \\
94.4 \%\end{array}$ & $\begin{array}{c}46 \\
69.7 \%\end{array}$ & \multirow{2}{*}{0.001} & \multirow{2}{*}{7.391} & \multirow{2}{*}{ 2.061-26.511 } \\
\hline No Blues & $\begin{array}{c}3 \\
5.6 \%\end{array}$ & $\begin{array}{c}20 \\
30.3 \%\end{array}$ & & & \\
\hline
\end{tabular}

$\mathrm{p}:<0.05$

According to Kennerly's maternity blues scale, all respondents who displayed maternal blues (94.4\%) also showed maternal blues when using Suryani's maternal blues scale. In comparison, of all respondents who were not characterized as having postpartum blues using Kennerly's maternity blues scale, 69.7\% were found to have the blues when using Suryani's maternal blues scale. These findings reveal a significant correlation between Kennerly's maternity blues scale and Suryani's maternal blues scale (.001). Suryani's maternal blues scale has a 7.391 times greater chance of finding maternal blues cases than Kennerly's maternity blues scale.

The diagnostic test value is: Sensitivity: a: $(\mathrm{a}+\mathrm{c})=51 / 54=0.94$;

Specificity: d: $(b+d)=20 / 66=0.30$, Positive predictive value $(\mathrm{PPV}): \mathrm{a}:(\mathrm{a}+\mathrm{b})=51 / 97=0.52$ Negative predictive value $(\mathrm{NPV}): \mathrm{d}:(\mathrm{c}+\mathrm{d})=$ $20 / 23=0.86$.

Likelihood ratio positive $(\mathrm{LR}+)=$ Sensitivity: $(1-$ Specificity $)=0.94 / 0,7=1.34$

Likelihood ratio negative (LR-) = (1-Sensitivity): Specificity $=0.06 / 0.30=0.2$.

\section{Discussion}

This study produced a maternal blues scale that measures postpartum attachment bonding to predict postpartum blues. The result of study identified 32 items that are valid and reliable in describing the affective state of postpartum blues through bonding attachment. The study also identified factors related to postpartum blues, both internal (maternal roles and tasks) and external (supporting sources in terms of culture, social, and economic support). Both subscales (internal and external factors) were used as a whole in this maternal blues scale, but the analysis process was done separately.

The roles and duties of mothers that are expressed as internal factors can describe the affective domain conditions of postpartum blues in terms of skin-to-skin contact, rooming in, breastfeeding, physical adaptation, and responsibility. The use of the compatibility of the mother's role and task factors through postpartum bonding 
attachment behavior to predict postpartum blues is in accordance with previous research. Bonding attachment in the postpartum period begins at birth through skin-toskin contact, breastfeeding, rooming in, and communication. ${ }^{24}$ Maigun Edhborg, Nasreen, and Kabir (2011) observed that depression inhibited the mother's interaction with her baby as the response decreased, limiting interaction with infants. At times, the bonding attachment process is hampered, resulting in an angry attitude when interacting and possibly leading to injuring a baby. Changes in the affective domain in interacting with infants occur when postpartum blues progress to the point of severe depression..$^{25}$ Previous measurements involving mothers' roles and duties through mother and baby interactions have not been used to measure postpartum blues. The results of the current study can enrich approaches for predicting postpartum blues (as shown in Table 3)

As with external factors (i.e., supporting sources including cultural, social, and economic support) are items that can predict the occurrence of postpartum blues. This statement is proven based on the indicators of the value of validity and reliability obtained. Family acceptance of infants was one of the cultural factors in this study that affected the condition of the affective realm of the mother in interacting with the baby. The presence of an unwanted or family-approved baby may stem from the sex of the baby, a marriage that is not approved by both families, or an unmarried pregnancy. ${ }^{26}$ Cultural traditions in Indonesia include marriage involving the blessing of both parents. Moreover, some ethnicities still emphasize one sex of the child as qualifying to be the family successor and impose restrictions on activities and prohibitions for postpartum mothers. Such factors can influence a woman to refuse to have children. Recognizing this problem can be a source of support for changes in the affective domain in interacting with babies that describe postpartum blues.

Gjerdingen, Froberg, and Fontaine (1991) stated that social support was one factor that could affect the physical and mental health of the mother. The most critical support is emotional support and information support in the types of help, assistance, and mentoring in areas such as housework. Support can be obtained from the husband or the people around him, including parents or parentsin-law. ${ }^{27}$ The type of social support that affects mothers who experience postpartum depression in Asian countries includes informational and emotional (affection) support and approval. ${ }^{24}$ The results of the current study agree with these findings

Family economic factors can also serve as predictors of postpartum blues. This assertion is in accordance with the previous studies. The complex problem experienced by Indonesian people is due to economic factors, especially low income. ${ }^{18}$ This factor affects the condition of the mother's emotional affective domain. ${ }^{18}$ Economic problems can be found in any ethnicities in Indonesia. Economic problems and their effects on the mother during the perinatal period are not only found in Indonesia but also occur in other ASEAN countries. For example, in India and Malaysia, the problem of low family income triggers postpartum depression. ${ }^{28}$

For social support and approval, the analysis of each of these items appeared to indicate that they were not reliable, but when all items were compiled and analyzed in order to predict the postpartum blues, that variable was shown to be valid and reliable. Important information that this study found was that the social support involving emotional, appraisal, informational, economic, and cultural factors combined are vital considerations in exploring the failure of mothers to interact with their infants as described by postpartum blues on the part of the mother. This result is in line with a previous study that demonstrated the significant influence of social support on the failure of bonding attachment and postpartum blues for mothers. ${ }^{29}$ The findings of the current study show that Suryani's maternal blues scale has 7.391 times the likelihood of finding maternal blues cases compared with Kennerly's maternity blues scale due to including these factors in the measured items.

Previous measurements such as cultural, social, and economic support have not been used in measuring instruments to explore the affective domain in interacting with infants in predicting postpartum blues. This study purports to be able to predict postpartum blues. Thus, the results of the current study promise to add a variety of ways to predict postpartum blues. 


\section{Conclusion}

The maternal blues scale can predict postpartum blues through an exploration of the affective domain when mothers interact with infants. This scale was constructed from two factors, internal (the role and duties of the mother) and external (supporting resources in the form of cultural, social, and economic support), that are related to the occurrence of postpartum blues. The development of these factors yielded 32 statement-based items that can predict postpartum blues having validity and reliability that meet the necessary indicators. The maternal blues scale that has been developed can therefore be declared suitable as a scale to predict postpartum blues. The results of this study that it provide an instrument to predict postpartum blues. This scale is consequently recommended as a postpartum assessment tool that can be used by nurses and midwives in hopes of decreasing the risk of postpartum depression and increasing the health of mothers and babies.

\section{Research Limitations}

This study had two limitations. First, the characteristics of the population did not reflect the ethnic diversity of all ethnicities in Indonesia. The scale still requires the development of demographic factors from other provinces in Indonesia. Second, the scale needs a broader study to explore cultural factors in predicting postpartum blues to be able to describe the overall cultural traits that exist in Indonesia.

\section{Acknowledgments}

We are grateful to the University of Indonesia that funded this study under scheme Pitta 2018 and the Jakarta I Health Polytechnic that facilitated the completion of this study. Likewise, we are thankful for the postpartum mothers in the South Jakarta DKI Community Health Centers who participated in the study.

\section{References}

1. Castle J. Early detection of postpartum depression: screening in the first two to three days. J Lancaster Gen Hosp [Internet]. 2008;3(4):147-9. Available from: http:// jlgh.org/JLGH/media/Journal-LGH-MediaLibrary/Past\%20Issues/Volume\%203\%20-\%20 Issue\%204/V3n4_Castle.pdf.

2. Jessica G, Gray R. Epidemiology of maternal mental health disorders. In: Martin CR, editor. Perinatal Mental Health: A Clinical Guide. first. London: M\&K Publishing; 2012. pp. $1-11$.

3. Ismail RI. Ante partum depression and husband's mental problem increased risk maternity blues. Med J Indones. 2006;15(2):74-80.

4. Manurung S, Lestari TR, Suryati B, Miradwiyana B, Karma A. Effectiveness of music therapy on prevention of postpartum blues in primipara mothers in the midwifery room of Cipto Mangunkusumo General Hospital, Jakarta. Bull Heal Syst Res. 2011;14(1):17-23.
5. Edhborg M, Matthiesen S, Lundh W, Widstrom M. Some early indicators for depressive symptoms and bonding 2 months postpartum - a study of new mothers and fathers. Arch Womens Ment Heal [Internet]. 2005;8:221-31. Available from: https://link. springer.com/article/10.1007/s00737-0050097-5

6. Klempner LG. Perspectives on risk factors, screening, and diagnosis. In: Stone SD, Menken AE, editors. Perinatal and Postpartum Mood Disorder: Perspectives and Treatment Guide for the Health Care Practitioner. New York: Springer Publishing Company; 2008. pp. 1-213.

7. Belsky J, Fish M, Isabella R. Continuity and discontinuity in infant negative and positive emotionality: family antecedents and attachment consequences. Dev Psychol [Internet]. 1991;27(3):421-31. Available from: https://doi.org/10.1037/00121649.27.3.421\%0A
8. Benoit D. Infant-parent attachment Definition, types, antecedents, measurement and outcome. Paediatr Child Health (Oxford) [Internet]. 2004;9(8):541-5. Available from: https://www.ncbi.nlm.nih.gov/pmc/articles/ PMC2724160/

9. Parfitt Y, Ayers S. The effect of postnatal symptoms of post-traumatic stress and depression on the couple's relationship and parent-baby bond. J Reprod Infant Psychol [Internet]. 2009;27(2):12742. Available from: http://dx.doi. org/10.1080/02646830802350831

10. Bornstein MH, Suwalsky JTD, Breakstone DA. Emotional relationships between mothers and infants: Knowns, unknowns, and unknown unknowns. Dev Psychopathol [Internet]. 2012;24(1):113-23. Available from: https:// www.ncbi.nlm.nih.gov/pubmed/22292998

11. Mantis I, Mercuri M, Stack DM, Field TM. Depressed and non-depressed mothers' touching during social interactions with their infants. Dev Cogn Neurosci [Internet]. 2018;35:57-65. Available from: https://doi. org/10.1016/j.dcn.2018.01.005 
12. Corrigan CP, Kwasky AN, Groh CJ. Social support, postpartum depression, and professional assistance: a survey of mothers in the Midwestern United States. J Perinat Educ [Internet]. 2015;24(1):48-60. Available from: http://doi.org/10.1891/1058-1243.24.1.48

13. Mercer RT. Becoming a mother versus maternal role attainment. J Nurs Scholarsh [Internet]. 2004;36(3):226-32. Available from: https:// doi.org/10.1111/j.1547-5069.2004.04042.x

14. Emmanuel EN. Maternal role development: the influence of maternal distress following childbirth. Midwifery [Internet]. 2011;27(2):265-72. Available from: https:// doi.org/10.1016/j.midw.2009.07.003

15. Klainin P, Arthur DG. Postpartum depression in Asian cultures: a literature review. Int J Nurs Stud [Internet]. 2009;46(10):1355-73. Available from: https://doi.org/10.1016/j. ijnurstu.2009.02.012

16. Bina R. The impact of cultural factors upon postpartum depression: a literature review. Health Care Women Int [Internet]. 2008;29(6):568-92. Available from: https:// doi.org/10.1080/07399330802089149

17. Rodrigues M, Nandita D. Gender, poverty, and postnatal depression: a study of mothers in Goa, India. Am J Psychiatry 2002; [Internet]. 2002;159(5):43-7. Available from: https://doi. org/10.1176/appi.ajp.159.1.43

18. Andajani-Sutjahjo S, Manderson L, Astbury J. Complex emotions, complex problems: understanding the experiences of perinatal depression among new mothers in urban Indonesia [Internet]. Vol. 31, Culture, Medicine and Psychiatry. 2007. pp. 101-22. Available from: https://doi.org/10.1007/ s11013-006-9040-0
19. Moslemi L, Tadayon M, Montazeri S, Tabari M, Gholamitabar,G. Prevalence and several effective factors on maternity blues. HealthMed [Internet]. 2012;6(7):2299-303. Available from: https://www.researchgate.net/ publication/282567893_Prevalence_and_ several_effective_factors_on_maternity_blues

20. Faisal-Cury A, Menezes PR, Tedesco JJA, Kahalle S, Zugaib M. Maternity blues: prevalence and risk factors. Span J Psychol [Internet]. 2008;11(2):593-9. Available from: https://www.ncbi.nlm.nih.gov/ pubmed/18988444

21. Cohen RJ, Swerdlik ME. Psychological Testing and Assessment: An Introduction to Tests and Measurement. 7th Edition. The McGraw-Hill Companies. Philadelphia : The McGraw-Hill Companies; 2010. 1-759 p.

22. Kaplan RM, Saccozzo DP. Psychological Testing Priciples, Applications and Issues. 6thedition . Lee J, Thomson Wadsworth. Philadelphia: Thomson LearningTM; 2005. pp.1-770.

23. Dahlan MS. Penelitian Diagnostik: Dasar-dasar Teoretis dan Aplikasi dengan Program SPSS dan Stata. 1stEdition. Aulia Novianty, editor. Salemba Medika. Jakarta: Salemba Medika; 2009. pp.1-152.

24. Edhborg M, Nasreen HE, Kabir ZN. Impact of postpartum depressive and anxiety symptoms on mothers' emotional tie to their infants 2-3 months postpartum: population-based study from rural Bangladesh. Arch Womens Ment Health [Internet]. 2011;14(4):307-16. Available from: https://www.ncbi.nlm.nih.gov/ pubmed/21626173
25. Moore ER, Anderson GC, Bergman N, Dowswell T. Early skin-to-skin contact for mothers and their healthy newborn infants. Cochrane Database Syst Rev [Internet]. 2014;16(5):1-118. Available from: https:// www.ncbi.nlm.nih.gov/pmc/articles/ PMC3979156/

26. O'Connor S. Child Neglect and Child Abuse. In: Perinatal Mental Health: a Clinical Guide. Philadelphia: M\&K Up Date; 2012. pp. 491-8.

27. Gjerdingen DK, Froberg DG, Fontaine P. The effects of social support on women's health during pregnancy, labor and delivery, and the postpartum period. Fam Med. 1991;23(5):370-5.

28. Manjunath NG, Venkatesh G, Rajanna. Postpartum blue is common in socially and economically insecure mothers. Indian J Community Med [Internet]. 2011;36(3):231-3. Available from: https:// dx.doi.org/10.4103/0970-0218.86527.

29. Ohara M, Okada T, Aleksic B, Morikawa M, Kubota C, Nakamura Y, et al. Social support helps protect against perinatal bonding failure and depression among mothers: a prospective cohort study. Sci Rep [Internet]. 2017;7(9546):1-8. Available from: https:// dx.doi.org/10.1038/s41598-017-087683.2008;23(3):323-8 